\title{
Recombinant Fibroblast Growth Factor 6
}

National Cancer Institute

\section{Source}

National Cancer Institute. Recombinant Fibroblast Growth Factor 6. NCI Thesaurus. Code C1369.

A recombinant therapeutic agent which is chemically identical to or similar to endogenous fibroblast growth factor 6 (FGF-6). Because of the mitog enic effects of FGF- 6 on fibroblasts and endothelial cells and the stimulatory effects of FGF- 6 on muscle stem cell migration, therapeutic FGF- 6 has a potential role in wound healing and muscle regeneration. ( $\mathrm{NCl04)}$ 